https://helda.helsinki.fi

\title{
Decreasing Trend in the Use and Long-Term Use of Benzodiazepines Among Young Adults
}

\section{Tähkäpää, Sanna-Mari}

2018-03-14

Tähkäpää , S-M , Saastamoinen , L , Airaksinen , M , Tuulio-Henriksson , A , Aalto-Setälä , T \& Kurko , T 2018 , ' Decreasing Trend in the Use and Long-Term Use of Benzodiazepines Among Young Adults ' , Journal of Child and Adolescent Psychopharmacology , vol. 28 , no. 4 , pp. 279-284 . https://doi.org/10.1089/cap.2017.0140

http://hdl.handle.net/10138/311658

https://doi.org/10.1089/cap.2017.0140

unspecified

acceptedVersion

Downloaded from Helda, University of Helsinki institutional repository.

This is an electronic reprint of the original article.

This reprint may differ from the original in pagination and typographic detail.

Please cite the original version. 


\section{Decreasing trend in the use and long-term use of benzodiazepines among young adults}


Objective Patterns of benzodiazepine (BZD) use and long-term use among young adults are not well known. Our aim was to study trends in BZD use and long-term use among 18-25-year-old young adults by gender and active substance in a nationwide retrospective longitudinal register-based setting.

Methods All Finns aged 18-25 years with reimbursed purchases of BZDs in 2006-2014 recorded to the Finnish Prescription Register were included. Annual prevalence rates of BZD use and long-term use among young adults were reported overall, and according to gender, drug group (anxiolytic or hypnotic) and active substance. Long-term use of BZDs was defined as purchasing $\geq 180$ Defined Daily Doses (DDDs) in at least two drug purchases during a calendar year.

Results Overall prevalence of BZD use among young adults decreased from 24.0 to 18.8 per 1000 inhabitants in 2006-2014. Prevalence of long-term use decreased from 5.5 to 3.3 per 1000 inhabitants. Overall BZD use was higher among females, whereas long-term use was more common among males. Use of anxiolytics was more common than use of hypnotics. Oxazepam, alprazolam, zopiclone and zolpidem were the most used BZDs, whereas alprazolam and clonazepam were the substances with most long-term use. The use and long-term use of BZDs have decreased annually since 2008 among Finnish young adults. Further research is needed to investigate the reasons behind the decline.

Keywords: Benzodiazepines, young adults, anxiolytics, hypnotics 


\section{Introduction}

Young adulthood is a developmentally critical phase associated with several challenges, such as achievement of independence, identity formation and important decision making for the future (Patel et al. 2007). Many mental disorders become prevalent during adolescence and young adulthood, and approximately three fourth of lifetime psychiatric disorders have emerged by the age of 24 (Kessler et al.2005). Studies have shown that psychotropic drug use has increased among adolescents and young adults in recent decades (Autti-Rämö et al 2009; Hsia et al 2009, Hartz et al. 2016). However, most of the pharmacoepidemiological research assessing the use and long-term use of BZDs has focused on adult population or the aged (Kurko et al. 2016) who consume BZDs more commonly than younger age groups and are at an increased risk for adverse effects associated with regular BZD use (Barker et al. 2004, Glass et al. 2005)

Previous studies on BZD use among young adults have concerned specific populations, such as patients with substance use disorders, or focus on abuse of BZDs (McCabe et al 2005, Kornor et al. 2010, Riska et al. 2014). In studies assessing BZD use in general populations, young adults have been included as one of the age-groups (Lagnaoui et al 2004, Cunningham et al. 2010, Hollingworth et al. 2010, Nordfjaern et al 2012, Olfson et al. 2015). In United States, the prevalence of BZD use was 2.6 $\%$ and $0.4 \%$ for long-term use among young adults (aged 18-35) (Olfson et al. 2015). In a Norwegian study cohort, $4 \%$ of young adults aged 18-25 years had received a prescription for BZDs, $1 \%$ used BZDs at least 180 DDD per year, and $0.5 \%$ were defined as chronic users (Nordfjaern et al. 2012). Among Taiwanese incident BZD users (aged 16-19), $5 \%$ were long-term users (Yeh et al. 2011)

There is limited population-based knowledge on the use of BZDs among young people due to the fact that most research has been conducted either among adults in general or among older adults (Kurko et al 2016). The objective of this study was to assess nationwide trends in the prevalence of BZD use and long-term use among young adults 18-25 years of age over a nine-year period of 2006-2014 overall and according to gender and active substance.

\section{Materials and Methods}

Data sources

This nationwide, retrospective register-based study is based on data from the Finnish Prescription Register of the Social Insurance Institution of Finland. The Finnish National Health Insurance covers 
all Finnish residents. The Prescription Register contains individual level information on all reimbursed drug purchases dispensed to Finnish residents in outpatient care. In the database, all drugs are classified according to the World Health Organization's, (WHO 2017) Anatomical Therapeutic Chemical (ATC) classification system. The data compiled for the present study contains information on each patient's personal identifier based on person's personal identification number in encrypted form, age at the end of the year, gender, ATC code of the dispensed drug, dispensing date, number of dispensed packages and number of defined daily doses (DDDs) dispensed. According to Finnish legislation, ethical approval was not required to conduct this register-based study with anonymized patient data. Permission to use data was given by the register holder, the Social Insurance Institution of Finland.

The BZDs included in this study are presented in supplementary table 1 . These were anti-epileptic clonazepam (ATC-code N03AE01), traditional BZD anxiolytics (N05BA), traditional BZD hypnotics (N05CD), BZD related drugs, also called z-hypnotics (N05CF) and combination of chlordiazepoxide and amitriptyline (N06CA01). Purchases of orally administered dosage forms were included in this study with the exception of oral suspensions.

The study population consisted of all 18-25-year-old young adults with at least one reimbursed purchase of BZD between 1 January 2006 and 31 December 2014. Young adults were selected as a study population because the majority $(94.3 \%, n=68167)$ of $0-25$-year-old BZD users $(n=72266)$ were 18-25-year-old young adults (Figure 1), and the definition for DDD by WHO (2016) concerns only adults. Person's age was calculated at the end of each calendar year. Numbers of BZD users, dispensed prescriptions and persons aged 0-25 covered by National Health Insurance in 2014 are presented in Figure 1.

\section{Study variable construction}

Anti-epileptic clonazepam was included in this study when used for other than epileptic indications, i.e. when purchased without special reimbursement for epilepsy. In the Finnish system, patients' entitlement for special reimbursement is based on doctor's certificate fulfilling certain diagnosis criteria. These purchases with special reimbursements are distinguished in a register with special 
coding. In the non-epileptic indications, the dosing is lower compared to dosing for epilepsy (8mg). The dosage of $1 \mathrm{mg}$ was used as the defined daily dose for clonazepam use based on the literature and clinical experience (White 2009, Drug and Alcohol Services 2012, Ashton 2013).

BZDs in ATC-classes N03AE01, N05BA, N06CA01 were classified as anxiolytics, and drugs in ATC-classes N05CD and N05CF as hypnotics.

Reimbursed drug purchase of BZDs was used as a proxy for BZD use (Haukka et al 2007). Longterm use of BZDs was defined as at least 180 DDD purchases of BZDs and two or more drug purchases during a calendar year corresponding to six months' use. This definition of six months' use was based on the WHO's recommendation as the definition for long-term use and a systematic review concerning long-term use BZD use (World Health Organization 1996; Kurko et al 2015). Drug consumption of BZDs per patient per year was calculated by using DDDs recommended by WHO (2016). DDDs of each patient's drug purchases were combined according to the patient's personal identifier.

One-year prevalence of BZD use and long-term BZD use were assessed overall and according to gender, drug group (anxiolytic or hypnotic, based on the ATC-classification) and active substance during 2006-2014. Prevalence rates (number of users per 1000 inhabitants) were calculated according to the number of the same age Finnish population.

\section{Statistical analysis}

While this study concerns a whole population, data were analyzed with descriptive statistical methods. Binomial distribution was used to compare changes in prevalence rates between 2006 and 2014. For these prevalence rates, the $95 \%$ confidence intervals were calculated. The overall yearly trends of each studied drug were assessed by comparing these confidence intervals. If the confidence intervals were not overlapping, the trend during the assessed period was considered to be statistically significantly changed. Descriptive data analyses were performed using statistical software IBM SPSS Statistics version 22.0 and binomial distribution was tested by R version 3.1.3.2015.

\section{Results}


Overall prevalence of BZD use among young adults decreased statistically significantly, by $21.5 \%$ from 24.0 to 18.8 / 1000 inhabitants over a nine-year period (Figure 2). The annual prevalence of BZD use increased between 2006 and 2008, the highest prevalence (28.6 / 1000 inhabitants) being observed in 2008. The use of BZDs was more common in females than males during the study period. In 2014, prevalence of BZD use among females was 22.8 / 1000 inhabitants and among males 15.1 / 1000 inhabitants.

Overall prevalence of long-term use of BZDs among 18-25-year-old Finns decreased statistically significantly, by $39.8 \%$ from 5.5 to 3.3 per 1000 inhabitants during 2006-2014. In 2014, the last studied year, $17.5 \%$ of all 18-25-year-old BZD users were defined as long-term users. The prevalence of long-term use was higher among males than females during the entire study period.

Use of anxiolytic BZDs was more common than use of hypnotics among Finnish young adults (Figure 3). The overall prevalence of anxiolytic use decreased 20.6\%, from 15.2 to 12.1 / 1000 inhabitants during the study period. The use of hypnotics decreased from 12.5 to 8.5 / 1000 inhabitants, $31.8 \%$ between 2006 and 2014. Long-term use of anxiolytics was more common than long-term use of hypnotics among young adults during the study period. In 2014, the prevalence of long-term use of anxiolytics was 2.6 / 1000 inhabitants and hypnotics 0.7 / 1000 inhabitants. Both long-term use of anxiolytics and long-term use of hypnotics decreased during 2006-2014.

Oxazepam and alprazolam were the most commonly used anxiolytics. The most commonly used hypnotics were z-drugs zopiclone and zolpidem. Over the nine-year study period, there was a decline in the use of almost every studied substance. Alprazolam use decreased the most $(53.5 \%)$ between 2006 and 2014. Only the prevalence of oxazepam use increased by $17.4 \%$, from 5.3 in 2006 to 6.2 per 1000 inhabitants in 2014. Use of diazepam and clonazepam was lower than that of oxazepam and alprazolam. During the study period, prevalence of diazepam use ranged between 2.0 and 3.4 / 1000 inhabitants, while clonazepam use ranged between 1.6 and 2.3 / 1000 inhabitants, respectively.

Long-term use of BZDs was relatively low among young adults during the study period. The highest prevalence of long-term use was observed in alprazolam users during 2006-2009 and in clonazepam users during 2010-2014. The substance-level prevalence of long-term use decreased in users of all BZD substances between 2006 and 2014. The decline of long-term use was most significant in diazepam (58.7\%) and alprazolam (57.9\%) users. Compared to other BZDs, long-term use was more 
prevalent among subjects using diazepam and clonazepam. The relative proportions of long-term use among diazepam and clonazepam users were higher compared to other BZDs. More than half (59.9$64.6 \%$ ) of clonazepam users were long-term users during 2006-2014. Corresponding proportions were $24.9-37.5 \%$ among diazepam users and 26.8-32.3\% among alprazolam users during the study period.

\section{Discussion}

To our best knowledge, the present study is the first nationwide register-based study focusing on use and long-term use of BZDs among young adults. Therefore, the present study offers clinically significant new information on BZD use and long-term use of this less studied user group. We found a decreasing trend of both BZD use and long-term use among Finnish young adults during the investigated nine-year study period. The overall prevalence of BZD use decreased by one fifth and long-term use of BZDs decreased by over one third between 2006 and 2014. Overall BZD use was more common among females, whereas long-term use was more common among males. The four most commonly used BZDs among young adults were oxazepam, alprazolam, zopiclone and zolpidem. Oxazepam was the only substance with increased use between 2006 and 2014. Alprazolam and clonazepam were the substances mostly used for long-term.

This study was based on data from the Finnish Prescription Register covering all reimbursed BZD purchases in Finland among whole population during the investigated period. Key strengths of this study are the nationwide data and a long nine-year study period. Completeness and accuracy of records in The Finnish Prescription Register is high.

Drug purchase was used as a proxy for BZD use, because there is concordance between prescription database information and self-reported BZD use (Haukka et al 2007). However, this study may underestimate the total BZD use among young adults in Finland. The Finnish Prescription Register does not record non-reimbursed drug purchases, inpatients' drug use or illegal drug use (Furu et al 2010). Moreover, some diazepam and oxazepam purchases in small package sizes are not recorded in the Prescription Register, as they are not usually reimbursable. The coverage of the register was 
76-90\% annually compared to wholesale data of BZD provided by the Finnish Medical Agency (2017). Information on patient's diagnosis or severity of psychiatric condition is not included in the Prescription Register.

Previous studies on BZD use and long-term use have varied considerably in terms of definition for long-term use, time-period of the study and age group making it difficult to compare the prevalence rates between studies. There may also be differences in treatment practices between countries. However, prevalence of BZD use (1.9\%) among Finnish young adults in 2014 was similar to that reported in France (1.8\%) but lower than reported in studies in the U.S. (2.6\%), Norway (4.0\%) and Taiwan (6.7\%) (Lagnaoui et al 2004, Yeh et al. 2011,Nordfjaern et al. 2012, Olfson et al. 2015). Long-term use of BZDs $(0.3 \%)$ by Finnish young adults was slightly less common than that reported among U.S. young adults (0.4 \%) in 2008 (Olfson et al. 2015), and among a sample of French young adults (0.6\%) in 2001 (Lagnaoui et al. 2004). Further, the prevalence of long-term use in Finland was lower than that observed in a Norwegian study cohort (1\%) during 2004-2008 (Nordfjaern 2012), and among Taiwanese incident BZD users (5 \%) in 2001-2005 (Yeh et al 2011).

It was not possible to include assessment of indications of BZD prescriptions in the present study. However, results showed that BZDs classified as anxiolytics were more commonly used than hypnotics, which may suggest that BZDs are more often used in anxiety than sleep disorders among young adults. At a substance-level, decreasing trend was observed among almost all BZDs except oxazepam, which was the only substance with increased use. In the last studied year, oxazepam was the most commonly used BZD among Finnish young adults. Increased use of oxazepam may be due to its lower abuse liability (Griffiths et al 1984). This study found that long-term use among oxazepam users was relatively uncommon. However, a recent study showed that oxazepam users were more prone to dose escalation compared with diazepam users (Tvete et al 2016). Despite the decreasing trend of long-term use overall and at a substance-level, long-term use was common among users of high or medium potency BZDs including clonazepam, diazepam and alprazolam. In this study, a majority of all clonazepam users used the substance for long-term. Similarly, a recent study found that clonazepam use is often associated with dose escalation (Alessi-Severini et al. 2016). On the other hand, in the study of Cloos et al. (2015), clonazepam was associated with a lower risk for highdose use compared to hypnotics and anxiolytics alprazolam and prazepam, which were associated with the highest risk for high-dose use. 
The observed gender difference in overall BZD use is consistent with other studies showing that use of BZDs is more common among females than males (Petitjean et al. 2007, Lagnaoui et al 2004, Cunningham et al. 2010, Olfson et al 2015). The higher prevalence of anxiety and sleep disorders in females during young adulthood partly explains this finding (Wittchen et al. 1998, Suvisaari et al. 2009). Yet, in our study, long-term use of BZDs was more prevalent in males than females. This could be partly explained by the previous finding reporting non-medical, e.g. self-reported possible abuse or misuse, use of anxiolytics and hypnotics in adolescence to be significantly more common in males than females in Finland compared to many other European countries (Kokkevi et al 2008). However, our study did not assess the possible abuse of BZDs.

Decreasing trend in BZD use found in this study suggests that prescribing patterns of BZDs have changed during recent years. Similar decreasing trend of BZD utilization has also been observed in the entire Finnish population (Saastamoinen et al. 2016). National guidelines on rational BZD prescribing recommend to restricting the length of BZD treatment to some weeks (National Supervisory Authority for Health and Welfare 2015, Working Group set up by the Finnish Medical Society Duodecmin and the Finnish Sleep Research Society 2017). However, we found that nearly one out of five young adult BZD users could be defined as a long-term user. Decreasing trend of longterm BZD use among young adults raises questions about the factors associated with decreased use. It is probable that a part of BZD use has been replaced by other pharmaceutical use or psychosocial treatments. During recent years, mental health services among adolescents and young adults have increased, which reflects the enhanced recognition of the treatment need, but may also suggest that stigma associated with mental health service use has decreased (Pylkkänen and Laukkanen 2011). Availability of mental health services may have improved, and low threshold online therapies are available, too (Stenberg et al 2016).

Based on the findings of this study we suggest that patterns of BZD long-term use among young people need more research. Long-term treatment with BZDs can be considered medically justified for some patients. Therefore, it would be of importance to identify specific patient groups, which would benefit from long-term BZD treatment. However, equally important would be to recognize those patients who may experience harm of BZD use.

In conclusion, both overall use and long-term use of BZDs have decreased annually since the year 2008 among Finnish young adults. Decreasing use may be the consequence of increased awareness of problems related to long-term BZD use and recommendations introduced to rationalize the use of 
BZDs. Further research is needed to identify factors associated with the decline in BZD use among young adults.

\section{Clinical Significance}

293 In this first nationwide study on BZD use and long-term use focusing on young adults, we found a

294 declining trend in use and long-term BZD use. Despite this decline, still a nearly one out of five 295 young adult BZD users could be defined as a long-term user and part of this long-term use may also be inappropriate. Our findings urge physicians to pay more attention to BZD prescribing and monitoring for young men who are especially prone to long-term use. In addition, special concern regarding the prescription practices of high potency BZDs alprazolam and clonazepam is needed, as these substances were most commonly used for long-term.

\section{Conflicts of interest} Tähkäpää: Have no conflicts of interests

Terhi Kurko has owned a few stocks of pharmaceutical company Orion Pharma in 2014-2015 and has received an expert fee from Pfizer in 2015.

\section{References}

Alessi-Severini S, Bolton JM, Enns MW, Dahl ME, Chateau D, Collins DM, Sareen J. Sustained Use of Benzodiazepines and Escalation to High Doses in a Canadian Population. Psychiatr Serv 67:1012-1018, 2016.

Ashton H. Benzodiazepines: How they work and how to withdraw. 2013 Available at: http://www.benzo.org.uk/manual/bzcha01.htm. Accessed Jun 14, 2017. adolescents and young adults has increased during 2000's]. Suomen lääkärilehti - Finlands läkartidning 315 64:477-482, 2009. 
Barker MJ, Greenwood KM, Jackson M, Crowe SF. Persistence of cognitive effects after withdrawal from long-term benzodiazepine use: a meta-analysis. Archives of Clinical Neuropsychology 4;19(3):437-454, 2004.

Cloos J, Bocquet V, Rolland-Portal I, Koch P, Chouinard G. Hypnotics and Triazolobenzodiazepines - Best Predictors of High-Dose Benzodiazepine Use: Results from the Luxembourg National Health Insurance Registry. Psychother Psychosom 84:273-283, 2015.

Cunningham CM, Hanley GE, Morgan S. Patterns in the use of benzodiazepines in British Columbia: Examining the impact of increasing research and guideline cautions against long-term use. Health Policy 97:122-129, 2010

Drug and Alcohol Services South Australia, Government of South Australia. Benzodiazepine conversion chart. Adelaide, Australia, 2012.

Finnish Medicines Agency Fimea. Drug consumption in years 2012-2015. Available at: http://raportit.nam.fi/raportit/kulutus/laakekulutus.pdf. Accessed Jun 14, 2017.

Furu K, Wettermark B, Andersen M, Martikainen JE, Almarsdottir AB, Sørensen HT. The Nordic Countries as a Cohort for Pharmacoepidemiological Research. Basic Clin Pharmacol Toxicol 106(2):86-94, 2010.

Glass J, Lanctôt KL, Herrmann N, Sproule BA, Busto UE. Sedative hypnotics in older people with insomnia: meta-analysis of risks and benefits. BMJ 331(7526), 2005.

Griffiths RR, McLeod DR, Bigelow GE, Liebson IA, Roache JD, Nowowieski P. Comparison of diazepam and oxazepam: preference, liking and extent of abuse. J Pharmacol Exp Ther 229:501-508, 1984.

Hartz I, Skurtveit S, Steffenak AKM, Karlstad $\varnothing$, Handal M. Psychotropic drug use among 0-17 year olds during 2004-2014: A nationwide prescription database study. BMC Psychiatry 16:12, 2016.

Haukka J, Suvisaari J, Tuulio-Henriksson A, Lönnqvist J. High concordance between self-reported medication and official prescription database information. Eur J Clin Pharmacol 63:1069-1074, 2007.

Hollingworth SA, Siskind DJ. Anxiolytic, hypnotic and sedative medication use in Australia. Pharmacoepidemiol Drug Saf 19:280-288, 2010.

Hsia Y, MacLennan K. Rise in psychotropic drug prescribing in children and adolescents during 1992-2001: A population-based study in the UK. Eur J Epidemiol 24:211-216, 2009

Kessler RC, Berglund P, Demler O, Jin R, Merikangas KR, Walters EE..Lifetime prevalence and age-of-onset distributions of DSM-IV disorders in the National Comorbidity Survey Replication. Arch Gen Psychiatry 62:593-602, 2005.

Kokkevi A, Fotiou A, Arapaki A, Richardson C. Prevalence, Patterns, and Correlates of Tranquilizer and Sedative Use among European Adolescents. J Adolesc Health 43:584-592, 2008.

Kornor H, Pedersen W, von Soest T, Rossow I, Bramness JG. [Use of benzodiazepines and cannabis in young adults]. Tidsskr Nor Laegeforen 130:928-931, 2010. 
Kurko TAT, Saastamoinen LK, Tähkäpää S, Tuulio-Henriksson A, Taiminen T, Tiihonen J, Airaksinen MS, Hietala J. Long-term use of benzodiazepines: Definitions, prevalence and usage patterns - A systematic review of register-based studies. Eur Psychiatry 30:1037-1047, 2016.

Lagnaoui R, Depont F, Fourrier A, Abouelfath A, Bégaud B, Verdoux H, Moore N.Patterns and correlates of benzodiazepine use in the French general population. Eur J Clin Pharmacol 60:523-529, 2004.

McCabe SE. Correlates of nonmedical use of prescription benzodiazepine anxiolytics: Results from a national survey of U.S. college students. Drug Alcohol Depend 79:53-62, 2005.

National Supervisory Authority for Welfare and Health. Prescribing Benzodiazepines. 2015 Available at: http://www.valvira.fi/terveydenhuolto/hyvaammatinharjoittaminen/laakehoito/bentsodiatsepiinien_maaraaminen_2. Accessed Jun 14, 2017.

Nordfjærn T A population-based cohort study of anxiety, depression, sleep and alcohol outcomes among benzodiazepine and z-hypnotic users. Addict Behav 37:1151-1157, 2012.

Olfson M, King M, Schoenbaum M. Benzodiazepine use in the United States. JAMA Psychiatry 72:136-142, 2015.

Patel V, Flisher AJ, Hetrick S P, McGorry P. Mental health of young people: a global public-health challenge. Lancet; 369:1302-1313, 2007.

Pylkkänen K, Laukkanen E (2011) [Adolescents do not fear the use of mental health services] Suomen lääkärilehti - Finlands läkartidning 66:2316-2317.

Riska BS, Skurtveit S, Furu K, Engeland A, Handal M. Dispensing of benzodiazepines and benzodiazepinerelated drugs to pregnant women: A population-based cohort study. Eur J Clin Pharmacol 70:1367-1374, 2014

Saastamoinen LK, Kalliokoski A, Martikainen J, Voipio T. Medicines in 2015. In: Finnish Statistics on Medicines 2015. Finnish Medicines Agency Fimea and The Social Insurance Institution, 2016. Available at: https://www.fimea.fi/documents/160140/1188389/Suomen_I\%C3\%A4\%C3\%A4ketilasto_2015.pdf/a813fea c-1560-4cbf-80e1-44049449e0bf Accessed Jun 13, 2017.

Stenberg J, Sequeiros SB, Holi M, Kampman O, Kieseppä T, Korkeila J Mäki P, Wahlbeck K, Joffe G, Häll P, Joutsenniemi K. [Mental health through ePsychiatry?] Suomen lääkärilehti - Finlands läkartidning 71:21062111a, 2016.

Suvisaari J, Aalto-Setälä T, Tuulio-Henriksson A, Härkänen T, Saarni SI, Perälä J, Schreck M, Castaneda A, Hintikka J, Kestilä L, Lähteenmäki S, Latvala A, Koskinen S, Marttunen M, Aro H, Lönnqvist J. Mental disorders in young adulthood. Psychol Med 39:287-299, 2009.

Tvete IF, Bjorner T, Skomedal T. A 5-year follow-up study of users of benzodiazepine: starting with diazepam versus oxazepam. Br J Gen Pract 66:e241-247, 2016.

White MP. Medication dosing in anxiety disorders: What the evidence shows. Prim Psychiatry 16:21-28, 2009. 
385 Wittchen HU, Nelson CB, Lachner G. Prevalence of mental disorders and psychosocial impairments in 386 adolescents and young adults. Psychol Med 28:109-126, 1998.

387 Working group set up by the Finnish Medical Society Duodecim and the Finnish Sleep Research Society.

388 Insomnia. Current Care Guideline, 2017. Available at:

389 http://www.kaypahoito.fi/web/kh/suositukset/suositus?id=hoi50067. Accessed Oct 18, 2017.

390 World Health Organization Rational use of benzodiazepines. 1996

391 World Health Organization. ATC/DDD Index 2017. Available at: http://www.whocc.no/atc_ddd_index/.

392 Accessed Jun 14, 2017.

393 World Health Organization: DDD. Definition and general considerations. 2016 Available at:

394 http://www.whocc.no/ddd/definition_and_general_considera/. Accessed Jun 14, 2017.

395 Yeh HH, Chen CY, Fang SY, Chang IS, Wu EC, Lin KM. Five-year trajectories of long-term benzodiazepine use

396 by adolescents: patient, provider, and medication factors. Psychiatr Serv 62:900-907, 2011. 